- The use of posterior composites appears to be increasing.

- Techniques used are in line with current thinking.

- For posterior composites there is some confusion over the need for rubber dam and use of lining materials.

- There is also confusion over the most appropriate restorative material to use in a pregnant patient.

\title{
Attitudes of general dental practitioners in the UK to the use of composite materials in posterior teeth
}

\author{
A. S. M. Gilmour, ${ }^{1}$ P. Evans ${ }^{2}$ and L. D. Addy ${ }^{3}$
}

Objective To determine the opinions and current methods used in placing posterior composite restorations by general dental practitioners. Setting The study was completed by general dental practitioners randomly selected from across the UK.

Method A questionnaire was devised to gain this information. It was sent to 500 UK dentists chosen at random from the general dental register, with an explanatory letter and reply-paid envelope.

Results Two hundred and sixty-seven replies were received. Sixtyone percent of dentists felt amalgam use had decreased over the last five years, 75\% felt posterior composite use had increased. Regarding choice of posterior material, almost all cited clinical indication as the most influential factor while patient's aesthetic demands (89\%), wish for a certain material (78\%) and the dentist's confidence using a certain restorative material (76\%) were contributing factors. Regarding the techniques used, contemporary techniques were employed although there was confusion regarding the need for rubber dam and the most appropriate method of lining the cavity. A case scenario of a pregnant patient who required treatment found that $66 \%$ of respondents would place a restoration other than a temporary dressing, with $16 \%$ placing an amalgam restoration.

Conclusions The majority of dentists surveyed place load bearing posterior composite restorations regularly. Their choice of restorative material is influenced by clinical indications and the patient's aesthetic demands. The techniques used were appropriate, although there was confusion around the need for rubber dam and the most appropriate method to line the cavity. There was also confusion in relation to the most appropriate materials for use in pregnancy.

\footnotetext{
${ }^{1}$ Senior Lecturer/Honorary Consultant in Restorative Dentistry, ${ }^{2}$ Dental Practitioner, ${ }^{3}$ Consultant in Restorative Dentistry, Department of Adult Dental Health, Cardiff University Dental Hospital, Heath Park, Heath, Cardiff, CF14 4XY ${ }^{*}$ Correspondence to: Dr Alan Gilmour

Email: gilmour@cardiff.ac.uk
}

\section{Online article number E32}

Refereed Paper - accepted 14 December 2006

DOI: $10.1038 /$ bdj.2007.472

${ }^{\circledR}$ British Dental Journal 2007; 202: E32

\section{INTRODUCTION}

Posterior composite restorations have evolved over many decades $^{1}$ and the materials and techniques available now are greatly improved. Concern over their longevity has reduced as clinical studies suggest that this now matches that of amalgam..$^{2,3}$ Indeed, a recent retrospective study of composite use in general practice found them to have a survival rate slightly higher than that of amalgam, with $91.7 \%$ at five years and $82.2 \%$ at ten years compared to amalgam's $89.6 \%$ and $79.2 \%$ respectively. ${ }^{4}$

In the UK, the 1998 Adult Dental Health Survey suggested that posterior composites are being used infrequently, ${ }^{5}$ with $84 \%$ of all teeth being filled with amalgam. Burke et al., ${ }^{6}$ again in a UK study, suggested that, although the use of posterior composite was increasing, amalgam was still the most frequently used material for posterior teeth. They highlighted some valid reasons for this, such as financial considerations (as posterior composites were not then available on the NHS), the clinician's lack of confidence in the techniques and the time-consuming nature of placing such a restoration. However, looking at the worldwide perspective would suggest an increasing move towards composite and there is evidence that dental schools outside the UK are now teaching posterior composites as the main posterior restorative material. ${ }^{7}$ This may suggest that the UK is out of step with dental practice worldwide. The recent introduction of a new NHS dental contract in England and Wales may have an impact on this prescribing pattern, although concerns over the extra time posterior composite restorations take may slow this change. The British Association of Teachers of Conservative Dentistry recently discussed this issue and concluded that posterior composite teaching should increase in UK dental schools. Amalgam has been a very successful restorative material. Changes to undergraduate teaching need to be carefully considered as there are many complicated interrelated factors.

Composites have a number of advantages over amalgam, ranging from the obvious ones, such as aesthetics and no mercury 
content, to the less obvious, such as the possibility of a reduced cavity size or reduced risk of cusp fracture. It is therefore appropriate to assess the dental profession's attitude towards posterior composites in the UK and to ask the practising dentist what they feel is the future of posterior restorative materials.

The aim of this study was to assess UK general dental practitioners' (GDPs') attitudes towards posterior composites and the methods they employ when completing them. The study also asked whether GDPs felt that posterior composite use is likely to increase with time. Finally, the use of restorative materials in pregnancy was asked of the respondents.

\section{MATERIALS AND METHODS}

A questionnaire was developed mirroring and extending that from a similar study. ${ }^{6}$ The questionnaire consisted of open and closed structured questions on posterior composite restorations and also included a free response section (the questionnaire is available, on request, from the corresponding author). It was first piloted amongst 15 GDPs and minor modifications were made. The questionnaire was then sent to 500 dental practitioners who were selected at random from the general dental register. After a period of four weeks the questionnaire was re-sent to all GDPs who had not responded to the first questionnaire. The data collected from the returned questionnaires was entered in an Excel database (Microsoft Inc. ${ }^{\odot}$ ), where the results were collated.

The questionnaire was divided into eight sub-sections to collect data on the following:

1. General information on the respondents

2. The treatment needs of patients

3. Factors affecting the choice of restorative materials used

4. Techniques used for posterior composites

5. Factors influencing the choice of composite used

6. General statements on posterior composites

7. A case scenario where the clinicians were asked to comment on the removal of caries and restoration of an MOD cavity in an UL6 in a pregnant woman (four months gestation) who presented to their practice in pain

8. The advantages and disadvantages of composite.

\section{RESULTS}

From the first mailing 211 replies were received, a response rate of $42 \%$. Eighty-eight more replies were received following the second mailing, giving an overall response rate of 299 $(60 \%)$. Thirty-two of the responses were blank, either because the dentist did not work with posterior composites (for example they were employed within an oral surgery setting) or because the dentist had retired or moved away from the address on the GDC register. The actual number of completed questionnaires totalled 267 (56\%). The following data is divided into the eight sub-sections relating to the questions asked in each section of the questionnaire.

\section{General information}

One hundred and fifty-eight responses (59\%) were from male dentists and 109 (41\%) were from female dentists. Table 1 shows age since qualification and the respondents' present position. Of the dentists sampled, 23 (9\%) worked in a NHS only practice, $10(4 \%)$ worked in a private only practice, 15 $(6 \%)$ worked in a community only practice, $3(1 \%)$ worked in

\begin{tabular}{|c|c|}
\hline Question & Number (\%) of respondents \\
\hline \multicolumn{2}{|c|}{ How long have you been qualified? } \\
\hline $0-5$ years & $23(9 \%)$ \\
\hline $5-10$ years & $37(14 \%)$ \\
\hline $10-15$ years & $38(15 \%)$ \\
\hline $15-20$ years & $41(16 \%)$ \\
\hline $20+$ years & $118(46 \%)$ \\
\hline \multicolumn{2}{|l|}{ Position in job } \\
\hline Practice owner & $131(50 \%)$ \\
\hline Associate & $91(35 \%)$ \\
\hline CDS & $22(8 \%)$ \\
\hline Corporate & $9(3 \%)$ \\
\hline Other & $11(4 \%)$ \\
\hline
\end{tabular}

Table 2 Factors influencing the choice of material chosen for a posterior restoration

\begin{tabular}{|l|l|l|l}
\hline Influencing factor & $\begin{array}{l}\text { Agree } \\
\mathrm{n}(\%)\end{array}$ & $\begin{array}{l}\text { Disagree } \\
\mathrm{n}(\%)\end{array}$ & $\begin{array}{l}\text { Don't } \\
\text { know } \\
\mathrm{n}(\%)\end{array}$ \\
\hline $\begin{array}{l}\text { Clinical situation } \\
\text { Patient's aesthetic demands }\end{array}$ & $233(97 \%)$ & $4(2 \%)$ & $2(1 \%)$ \\
\hline $\begin{array}{l}\text { Patient's wish for a certain } \\
\text { material }\end{array}$ & $204(78 \%)$ & $28(10 \%)$ & $2(1 \%)$ \\
\hline $\begin{array}{l}\text { Confidence using restorative } \\
\text { material }\end{array}$ & $200(76 \%)$ & $53(20 \%)$ & $10(4 \%)$ \\
\hline $\begin{array}{l}\text { Patient's financial situation } \\
\text { Refereed journals/update articles }\end{array}$ & $189(73 \%)$ & $62(24 \%)$ & $8(3 \%)$ \\
\hline $\begin{array}{l}\text { Patient's concerns about } \\
\text { amalgam safety }\end{array}$ & $188(72 \%)$ & $61(23 \%)$ & $14(5 \%)$ \\
\hline \begin{tabular}{l} 
Information in the dental press \\
\hline $\begin{array}{l}\text { Dentist's concerns about amal- } \\
\text { gam safety }\end{array}$
\end{tabular} & $92(35 \%)$ & $130(50 \%)$ & $40(15 \%)$ \\
\hline \begin{tabular}{l} 
Advertising \\
\hline
\end{tabular} & $18(7 \%)$ & $211(80 \%)$ & $33(13 \%)$ \\
\hline
\end{tabular}

a mixed NHS and community practice, and 213 (80\%) worked in a mixed private and NHS practice. The majority of dentists surveyed were in a position to offer posterior composite restorations to patients as a routine restorative treatment. When asked how many load bearing composites the dentists placed, $209(79 \%)$ said they placed more than one a month, 50 (19\%) said they placed less than one a month, and 5 (2\%) said they never placed load bearing occlusal composites.

\section{Treatment needs}

Regarding their views on how their clinical practice had changed in the last five years (Fig. 1), the majority reported that they felt the need for restorations in adults had not changed (70\%). Similarly 50\% reported that they felt the need for 
restorations had not changed in children. However, around $25 \%$ reported that they felt there had been a decrease in the need for restorations in that period for both adults and children. Over $60 \%$ of respondents reported a decreased use of amalgam in both adults and children, whilst the use of posterior composites in adults and non-amalgam use in children had increased by 75\% and 62\% respectively.

When asked what restorative material the dentist used most often to restore children's teeth, glass ionomer cement was the most common choice. Only a small proportion of respondents used composite and amalgam in children.

\section{Factors influencing the choice of restorative material used by dentists}

Table 2 shows factors that influenced dentists when clinically choosing the restorative material for an individual case. The clinical situation had the greatest influence on dentists when choosing a restorative material (97\% of respondents agreed). The patient's wishes, which included their aesthetic demands, preference for a certain type of material, concerns for amalgam safety and financial situation also featured highly as factors which affected a dentist's choice. Respondents also reported that refereed journal articles influenced their choice (72\% of respondents agreed). Advertising had little influence on their choice of material (7\% agreed).

\section{Factors influencing the choice of composite used}

The respondents were asked what influenced their choice of composite material in the posterior region (Fig. 2). The physical properties, handling characteristics and shrinkage of the composite material had the greatest influence over the type of composite that the dentists had chosen. The colour range for aesthetics was also important. Published research, delivery system and radiopacity were also reported to be important in the decision to purchase. Cost, manufacturer and advertising were less influential.

\section{Techniques used in the placement of extensive} posterior composite restorations

Table 3 shows what techniques dentists reported employing when providing extensive posterior composite restorations. Most dentists used incremental curing (89\% always did), with only three (1\%) never using it. Eighty-two percent reported always using some form of moisture control, but only $12 \%$ said that they routinely used rubber dam. There was a wide variation in the use of linings. Twenty-five percent reported never using a calcium hydroxide lining. Eight percent reported always using a thin glass ionomer (GIC) lining/base and 9\% reported using a thick GIC lining/base. Metal matrix bands were more commonly used compared to clear ones; 36\% reported never using a clear matrix band. With regard to bonding techniques, traditional total etch/dentine bonding agent was used most frequently (69\% of respondents reported always using this technique) than the newer self-etch/dentine bonding systems (14\% reported always using this technique).

\section{General statements}

The dentists were asked a series of questions to determine their views on posterior composite as a restorative material. The replies are shown in Table 4. Fifty-four percent of the respondents felt that the lifespan of a composite before it required replacement was similar to that of amalgam, although only $31 \%$ felt that composite would replace amalgam within the next ten years. In addition, very few dentists felt that the use of amalgam in the dental undergraduate curriculum would disappear in the next five years (10\%). Forty-five percent of dentists felt that changing over to composite would cause problems with the standard of care provided to patients.

Almost all dentists felt that placing composites in posterior teeth was more time-consuming than amalgam (98\%). Seventy-three percent felt that with increasing usage, the overall cost of oral healthcare in the UK would increase. In relation to changes in the NHS contract (England and Wales), 26\% of respondents felt that this would increase the number of posterior composites undertaken.

\section{Case scenario}

A case scenario was presented which related to a pregnant patient who was complaining of pain of a dental origin. This was diagnosed and the treatment plan proposed included removal of the MOD restoration and associated carious lesion in the UL6. Forty-nine respondents (16\%) said they would then restore the cavity with amalgam, 94 (30\%) said they would restore it with a posterior composite, $61(20 \%)$ said they would restore it with another restorative material and 108 (34\%) said they would restore it with a temporary dressing until after the baby was born.

\section{Advantages and disadvantages of composite}

The three main responses about the advantages of composite were aesthetics, the ability to bond to tooth tissue, and minimal removal of sound tooth tissue in cavity design. The disadvantages included the time-consuming nature of composite restorations, the increased cost coupled with worries about longevity, leakage and shrinkage of posterior composites, and the difficulties in achieving a good contact point in a class II cavity.

\section{DISCUSSION}

As dentistry embraces a new age in England and Wales with the newly introduced dental contract (April 2006), it would seem that many things are about to change within the dental profession. One thing that has not changed over the last 100 years, however, is the use of amalgam as a restorative material. Amalgam is still the material of choice for many UK dentists to restore posterior teeth, as it is strong, easy to work with and produces reliable results. Composite, which has been around for about 40 years, has not yet gained the same prevalence. The ADH survey (1998) undertaken in the UK found that amalgam was used for $84 \%$ of restorations, ${ }^{5}$ which is markedly different from studies in Australia, Finland and the United States, where composite accounts for a much larger proportion of restorations. $^{8-10}$ The study based in Finland reported that $75 \%$ of posterior teeth were restored with composite. ${ }^{8}$

A questionnaire study requires a good response rate to be effective. Tan and Burke ${ }^{10}$ suggested that an acceptable response rate was $64 \%$. This study achieved a $60 \%$ response rate, although only 56\% were usable because some respondents were not in a workplace environment (such as in hospital oral surgery units) where load bearing composite restorations were 


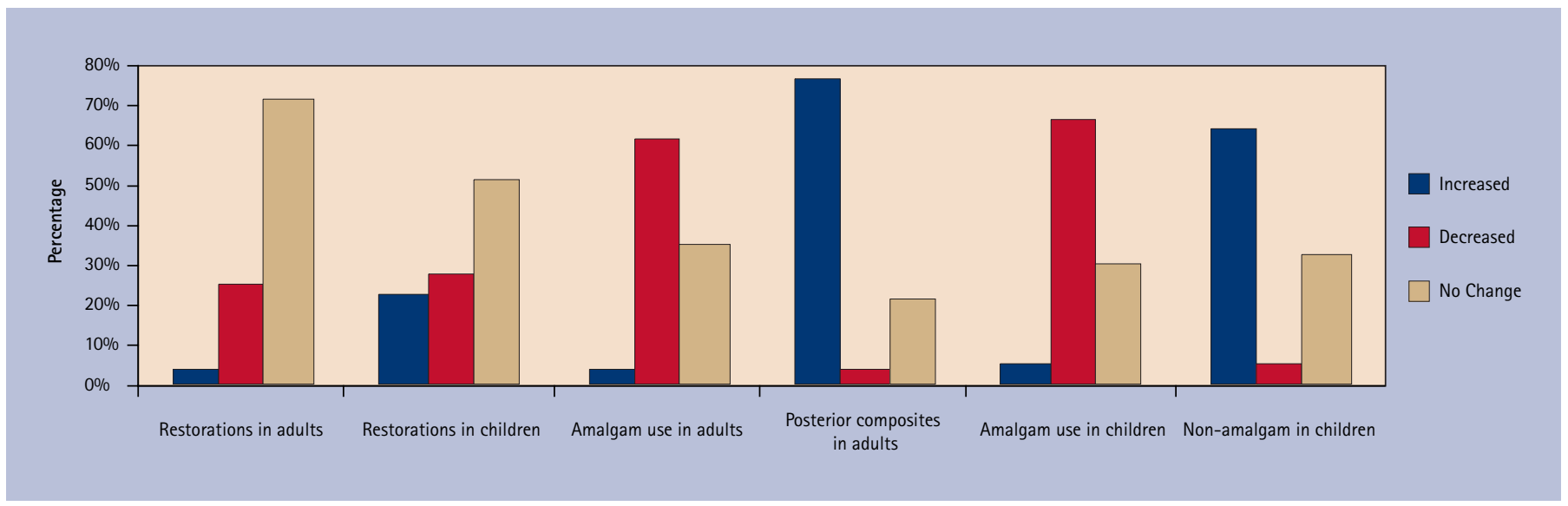

Fig. 1 Dentists' views on the use of restorations over the previous five years

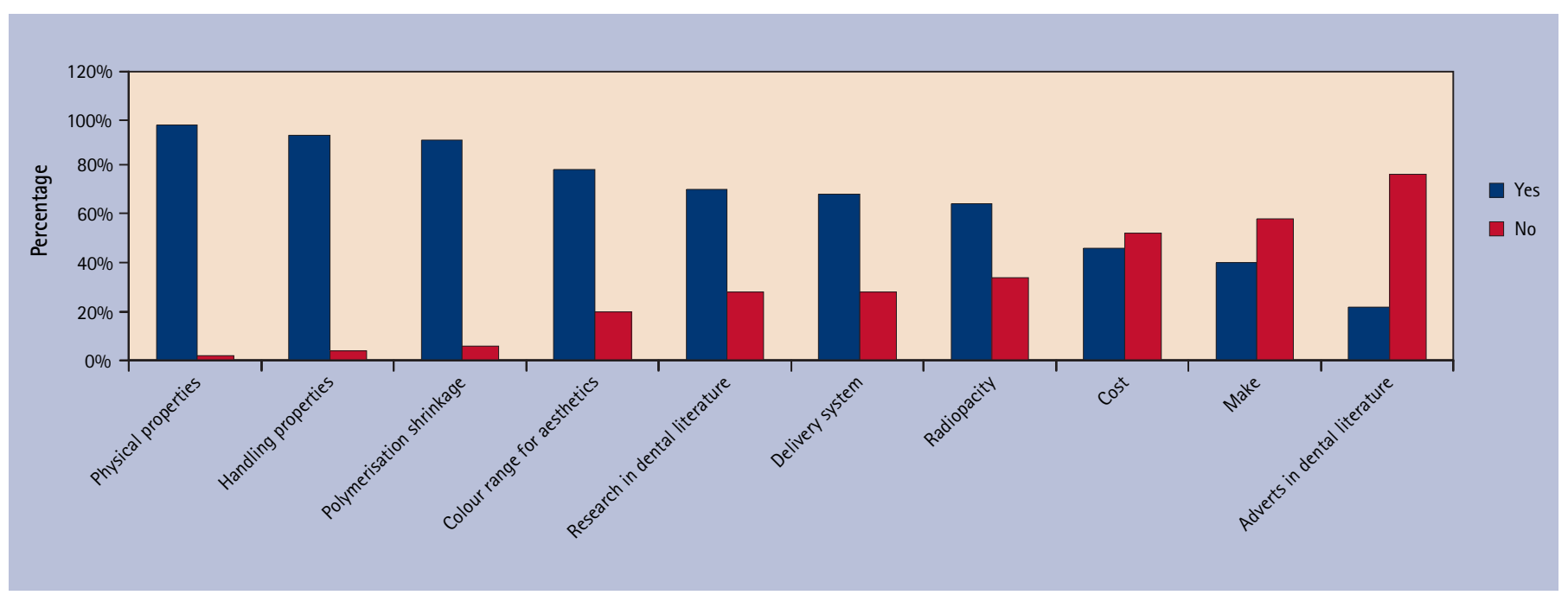

Fig. 2 Factors that influence the choice of composite used

routinely undertaken. There is also always the risk of sample bias, with only those interested in this area of clinical practice responding. We have attempted to interpret the results with these limitations in mind. Looking at those who replied, there was a slightly higher response rate from female dentists than would be expected from the dental register demographics. The majority of respondents worked in mixed NHS/private practices and the majority said they placed load bearing posterior composites on a regular basis.

The results (Fig. 1) indicate that the nearly 61\% of dentists feel that the need for restorations in adults has not changed much over the last five years. They also indicate that a high proportion of dentists feel that the amount of amalgam being used in adults has decreased, while the number of posterior composites that are completed has increased. In the UK, the NHS funding system previously in place precluded the use of posterior composites, although dentists in the UK increasingly provided posterior composites outside the NHS. Patients have also become more aware of the aesthetic benefits of a 'white filling' and the controversy over amalgam safety. The introduction of the new NHS dental contract in April 2006 in England and Wales may provide more scope for the increased use of posterior composite restorations, although this has yet to be seen. Increased confidence over the use and reliability of posterior composite filling materials may also encourage a change. ${ }^{4}$ This trend is reflected in our findings, with over $80 \%$ of the dentists surveyed in this questionnaire placing posterior composite restorations regularly. In children, the trend of decreasing amalgam use is marked, with over 63\% of dentists now placing non-amalgam restorations. One question that was not asked was whether dentists felt that the size of restorations had decreased over the five-year period. Smaller cavities may be more simply restored with composite type restorations.

The dentists were asked what factors influenced their choice of restorative material for a posterior restoration (Table 2). The clinical situation was the biggest influence for most dentists, with the patient's aesthetic demands and their wish to avoid certain restorative materials (such as amalgam) coming next. It would seem that the patient is having more influence on these clinical decisions, which although desirable, requires the patient to be fully informed. The indication from this study that many general dental practitioners considered the use of refereed journals an important influence on their decision process is encouraging. The increasing use of an evidence-based approach is helpful in this respect, although high quality longterm clinical studies based in primary dental care are rare. ${ }^{11}$ It is these studies that would have direct relevance to most dental practitioners. Interestingly, the majority of dentists did not feel that amalgam safety was a factor that influenced their decision. It is clear, however, that the profession needs to balance patient wishes with available clinical evidence on safe, predictable techniques and materials. ${ }^{12}$ 
Regarding the techniques used by dentists in placing extensive posterior composite restorations, it was encouraging to see that $60 \%$ of dentists surveyed used rubber dam either always or sometimes, an increase from the $47 \%$ recorded in a similar study. ${ }^{6}$ However, only $12 \%$ indicated that they always used rubber dam. There is some inconsistency within the literature with regard to the necessity of using rubber dam for posterior composites. Some state that it is always necessary, ${ }^{13,14}$ whilst others question its need, ${ }^{16}$ recording excellent longevity results without its use. Instead, other moisture control methods are used such as cotton wool rolls and aspiration..$^{15}$ A recent survey of the teaching of moisture control in relation to posterior composites in dental schools in the UK and Ireland found that all schools taught rubber dam placement. Thirteen out of the 15 also taught the use of cotton wool rolls and 11 taught the use of dry guards as alternative forms of moisture control. ${ }^{16}$ There is a lot of confusion regarding rubber dam use and the literature is unclear in this area, ${ }^{13,14,16}$ but the key would seem to be effective moisture control. Rubber dam does, however, offer other benefits which may also be of value.

Regarding the use of a cavity lining, there was a wide range of responses. The data were difficult to interpret here because respondents ticked a number of boxes in the questionnaire, but it would appear that a significant number of dentists are not using any lining material when placing a posterior composite restoration. We assume that instead they are relying on effective dentine bonding to seal the dentinal tubules and eliminate marginal leakage.

There is some variation in the undergraduate teaching of the use of lining materials under posterior composites ${ }^{16}$ and it is clear from this study that there is also variation within the dentists who replied. However, glass ionomer cement (GIC) is suggested for moderate to deep cavities by the majority of dental schools in the UK and Ireland. ${ }^{16}$ Research is again confused in this area, with some studies indicating that liners do not help post-operative sensitivity, ${ }^{17}$ whilst others are in favour of their use. ${ }^{18}$ The data in Table 3 indicate that most of the dentists are sometimes, but not always, placing a GIC lining and the mixture of figures seems to suggest a degree of confusion amongst dentists as to whether to place a GIC lining or not. Further work is required to clarify this area and provide clinical guidance.

Most of the dentists surveyed used some form of metal matrix as opposed to a clear band. This is of benefit, as research demonstrates that contact points are more accurate when a thin metal matrix is used, therefore helping to prolong the life of the restoration and reduce the risk of an overhang. ${ }^{19-21}$ However, the dentists were not asked what type of metal matrix band they were using and it is unknown how many were using metal bands specifically designed for amalgam rather than composite, as this would make achieving a tight contact point difficult. Most dentists were using an incremental curing technique, which is supported by the dental literature. ${ }^{22}$ Therefore in summary, it would appear that dentists are using contemporary techniques to complete their posterior composite restorations. However, there is some confusion with regard to the use of liners under composite restorations and the need for rubber dam isolation.

Respondents were also asked whether they felt that an increase in the number of posterior composite restorations

\begin{tabular}{|c|c|c|c|}
\hline Techniques & $\begin{array}{l}\text { Always } \\
\mathrm{n}(\%)\end{array}$ & $\begin{array}{l}\text { Sometimes } \\
\mathrm{n}(\%)\end{array}$ & $\begin{array}{l}\text { Never } \\
\text { n (\%) }\end{array}$ \\
\hline Incremental curing & $229(89 \%)$ & $26(10 \%)$ & $3(1 \%)$ \\
\hline $\begin{array}{l}\text { Use of moisture control } \\
\text { methods (not rubber dam) }\end{array}$ & $210(82 \%)$ & 35 (14\%) & $12(4 \%)$ \\
\hline Use of rubber dam & $29(12 \%)$ & $124(48 \%)$ & $103(40 \%)$ \\
\hline $\begin{array}{l}\text { Total etch/dentine } \\
\text { bonding agents }\end{array}$ & 177 (69\%) & $63(25 \%)$ & $17(6 \%)$ \\
\hline $\begin{array}{l}\text { Self-etch/dentine } \\
\text { bonding agents }\end{array}$ & $32(14 \%)$ & $95(42 \%)$ & $98(44 \%)$ \\
\hline Metal matrix band & $106(41 \%)$ & 141 (55\%) & $10(4 \%)$ \\
\hline Clear matrix band & $19(7 \%)$ & 143 (57\%) & $92(36 \%)$ \\
\hline Calcium hydroxide & $46(18 \%)$ & 147 (57\%) & $64(25 \%)$ \\
\hline Thin Gl base lining & $22(9 \%)$ & $164(65 \%)$ & $67(26 \%)$ \\
\hline Thick GI base lining & $21(8 \%)$ & 141 (56\%) & $88(36 \%)$ \\
\hline $\begin{array}{l}\text { Co-cure technique } \\
\text { (resin-modified GI) }\end{array}$ & $11(5 \%)$ & 112 (45\%) & $124(50 \%)$ \\
\hline
\end{tabular}

\begin{tabular}{|c|c|c|c|}
\hline Question & $\begin{array}{l}\text { Agree } \\
n(\%)\end{array}$ & $\begin{array}{l}\text { Disagree } \\
\mathrm{n}(\%)\end{array}$ & $\begin{array}{l}\text { No opinion } \\
\mathrm{n}(\%)\end{array}$ \\
\hline $\begin{array}{l}\text { It is possible to provide } \\
\text { a posterior composite } \\
\text { restoration with a lifespan } \\
\text { similar to amalgam }\end{array}$ & $140(53 \%)$ & $112(42 \%)$ & $13(5 \%)$ \\
\hline $\begin{array}{l}\text { Composite will eventually } \\
\text { replace amalgam in the } \\
\text { next ten years }\end{array}$ & 83 (31\%) & $133(50 \%)$ & $49(19 \%)$ \\
\hline $\begin{array}{l}\text { The standard of dentistry } \\
\text { would decrease if amalgam } \\
\text { was discontinued }\end{array}$ & 118 (45\%) & $102(38 \%)$ & $45(17 \%)$ \\
\hline $\begin{array}{l}\text { The increase in composite } \\
\text { use is increasing the total } \\
\text { cost of oral healthcare }\end{array}$ & $194(73 \%)$ & $38(14 \%)$ & $33(13 \%)$ \\
\hline $\begin{array}{l}\text { Composite restorations are } \\
\text { more time-consuming than } \\
\text { amalgam }\end{array}$ & 260 (98\%) & $2(1 \%)$ & $3(1 \%)$ \\
\hline $\begin{array}{l}\text { Changes to the NHS } \\
\text { contract will increase the } \\
\text { number of posterior com- } \\
\text { posites being carried out }\end{array}$ & $69(26 \%)$ & $108(41 \%)$ & 88 (33\%) \\
\hline $\begin{array}{l}\text { The teaching and clinical } \\
\text { experience of the use of } \\
\text { amalgam will disappear } \\
\text { in the undergraduate cur- } \\
\text { riculum in five years }\end{array}$ & $25(10 \%)$ & $165(62 \%)$ & 75 (28\%) \\
\hline
\end{tabular}

would increase the total cost of oral healthcare and 73\% said that they felt it would, with 98\% saying that they felt that posterior composite restorations take longer to complete than an amalgam restoration. This has been noted previously ${ }^{23}$ and if the current trend continues, is likely to have an effect on the total overall cost of dentistry in the UK. Dentists were asked 
what influenced their choice of posterior composite material (Fig. 2). Most considered the physical properties to be the most important factor, with handling properties and polymerisation shrinkage also playing an important role. Journal articles were also reported to be a factor, with over $70 \%$ reporting that this would have an influence.

It has been suggested that amalgam teaching in dental schools in the UK will be reduced and replaced with the teaching of posterior composites within five years. ${ }^{7}$ The dentists were asked for their views on this change, but only $9 \%$ agreed with this view (Table 4). Forty-five percent felt that the standard of dentistry would decrease if amalgam was discontinued, and $50 \%$ disagreed with the statement that 'composite will eventually replace amalgam in the next ten years'. These results would suggest that our respondents are currently not ready to give up the use of amalgam. A rapid change away from amalgam may in addition leave some clinicians without the relevant skills to completely convert. ${ }^{24}$ If dental schools decide to progressively reduce the teaching of amalgam restorations, then the profession may have no choice but to slowly convert to using composite. This may alarm some dentists, considering evidence supports the long-term success of amalgam as a restorative material and early studies disputed the suitability of composite as an alternative. ${ }^{24}$ More recent reports, however, indicate a failure rate similar to amalgam. ${ }^{2}$ In one study, composite was shown to have a longevity over ten years of $74.2 \% .^{26}$ These figures are influenced greatly by factors related to the patient, the dentist and the type of restorative material used. In addition, many of these studies are undertaken within a hospital rather than general practice setting, making the generalisation of this data questionable. ${ }^{12}$ One thing, however, does seem clear; teachers need to think carefully before they implement a composite-only teaching policy, and certainly a gradual rather than an abrupt change would seem prudent. ${ }^{27}$

Finally, the dentists were presented with a case scenario asking how they would treat a pregnant woman who needed a MOD filling in her UL6. A significant number reported that they would either place a posterior composite restoration or a temporary dressing, depending on the patient's financial situation. Nearly 16\%, however, said that they would place an amalgam restoration. The advice from the Department of Health in a joint statement by the Chief Dental Officer and Deputy Chief Medical Officer $^{28}$ is that it may be prudent to avoid, where clinically reasonable, the placement or removal of amalgam fillings during pregnancy... it is not recommended that other permanent, dental filling materials are routinely substituted for amalgam.' This guidance suggests that dentists avoid the use of amalgam (if possible) in pregnant patients and also avoid placing or replacing restorations with other permanent dental filling materials, which we assume includes materials such as composite. If glass ionomer is included as a "permanent dental filling' then over two-thirds of the dentists surveyed are currently not routinely following current recommendations. If glass ionomer is removed from this classification (this would not seem unreasonable) then this is still almost half of the respondents. The advice from the British Dental Association in such circumstances is to ensure that informed consent is gained before undertaking any intervention. Interestingly, a number of female dentists commented in this survey that these recommendations were slightly controversial considering that they advised stopping placing amalgam restorations in pregnant patients, but to continue doing so as a pregnant dentist.

Comparing this study to a similar one in $2001,{ }^{6}$ it seems clear that there is a trend of increasing posterior composite restoration placements. The effect of the new NHS contract on this trend is unknown at present. Changes to the undergraduate curriculum may be necessary to predict this trend, however, a rapid or complete change away from amalgam may cause problems with established dentists.

\section{CONCLUSION}

In the UK, dentists seem to be placing more posterior composite-type restorations then before. The techniques used seem in step with current knowledge, however two areas cause some difficulties or confusion. The routine use of rubber dam for such restorations is not occurring, although the evidence of rubber dam effectiveness is not clear from the available literature. There is also confusion about the use of linings beneath a posterior composite restoration. Both of these areas would benefit from high quality clinical research, preferably based in a primary dental care environment to help with the generalisability of that research. There is some concern that as composite restorations take longer to complete, there will be an increased cost involved in this trend. Finally, the questionnaire highlighted some confusion surrounding the appropriate treatment of a pregnant patient. Guidance given in a joint CDO/CMO statement only partially clarifies this.

1. Minguez N, Ellacuria J, Soler J I, Triana R, lbaseta G. Advances in the history of composite resins. J Hist Dent 2003; 51: 103-105.

2. Hickel R, Manhart J. Longevity of restorations in posterior teeth and reasons for failure. J Adhes Dent 2006; 3: 45-64.

3. Marghalani H Y, Al-jabab A S. Compressive creep and recovery of light-cured packable composite resins. Dent Mater 2004; 20: 600-610.

4. Opdam N J M, Bronkhorst E M, Joost M R, Loomans B A C. A retrospective clinical study on longevity of posterior composite and amalgam restorations. Dent Mater 2007; 23: 2-8.

5. Kelly M, Steele J, Nuttall N et al. Adult dental health survey. Oral health in the United Kingdom 1998. pp 112. London: TSO, 2000.

6. Burke F J T, McHugh S, Hall A C, Randall R C, Widstrom E, Forss H. Amalgam and composite use in UK general dental practice in 2001. Br Dent J 2003; 194: 613-618.

7. Lynch C D, McConnell R J, Wilson N H F. Challenges to teaching posterior composites in the United Kingdom and Ireland. Br Dent J 2006; 201: 747-750.

8. Forss $\mathrm{H}$, Widstrom E. From amalgam to composite: selection of restorative materials and restoration longevity in Finland. Acta Odonto/ Scand 2001; 59: 57-62.

9. Bogacki R E, Hunt R J, Aguila M, Smith W R. Survival analysis of posterior restorations using an insurance claims database. Oper Dent 2002; 27: 488-492.

10. Burke F J T, McHugh S, Randall R C, Meyers I A, Pitt J, Hall A C. Direct restorative materials use in Australia in 2002. Aust Dent J 2004; 49: 185-191.

11. Chadwick B L, Treasure E T, Dummer P M H et al. Challenges with studies investigating the longevity of dental restorations - a critique of a systematic review. J Dent 2001; 29: 155-161.

12. Gilbert J A. Posterior composites: an ethical issue. Oper Dent 1987; 12: 79-81.

13. Strydom C. Handling protocol of posterior composites. Rubber dam. SADJ 2005; 60: 292-293.

14. Terry D A. An essential component to adhesive dentistry: the rubber dam. Pract Proced Aesthet Dent 2005; 17: 106, 108.

15. Brunthaler A, Konig F, Lucas T, Sperr W, Schedle A. Longevity of direct resin composite restorations in posterior teeth. Clin Oral Investig 2003; 2: 63-70.

16. Lynch C D, McConnell R J, Wilson N H F. Teaching of posterior composite resin restorations in undergraduate dental schools in Ireland and the United Kingdom. Eur J Dent Educ 2006; 10: 38-43.

17. Unemeri M, Matsuya Y, Akashi A, Goto Y, Akamine A. Composite resin restoration and postoperative sensitivity: clinical follow-up in an undergraduate program. J Dent 2001; 29: 7-13

18. Akpata E S, Sadiq W. Post-operative sensitivity in glass ionomer versus adhesive resin-lined posterior composites. Am J Dent 2001; 14: 34-38

19. Peumans M, Van Meerbeek B, Asscherickx K et al. Do condensable composites help to achieve better proximal contacts? Dent Mater 2001; 17: 533-541.

20. Neiva I F, deAndrada M A C, Baratieri L N, Moneiro S, Ritter A V. An in vitro study of the effect of restorative techniques on marginal leakage in posterior composites. Oper Dent 1998; 23: 282-289. 
21. Mullejans R, Badawi M O F, Raab W H M, Lang H. An in vitro comparison of metal and transparent matrices used for bonded class II resin composite restorations. Oper Dent 2003; 28: 122-126.

22. Burke F J T, Shortall A C C. Successful restoration of load bearing cavities in posterior teeth with direct-replacement resin-based composite. Dent Update 2001; 28: 388-398

23. Mjor I A, Burke F J T, Wilson N H F. The relative cost of different restorations in the UK. Br Dent J 1997; 182: 286-289.

24. Opdam N J. The future of dental amalgam. Ned Tijdschr Tandheelkd 2005; 112: $373-375$.
25. Wilson N H F, Dunne S M, Gainsford I D. Current materials and techniques for direct restorations in posterior teeth. Part 2: resin composite systems. Int Dent J 1997; 47: 185-193.

26. Gaengler $\mathrm{P}$, Hoyer I, Montag R. Clinical evaluation of posterior composites restorations: the 10 year report. J Adhes Dent 2001; 3: 185-194.

27. Roeters F J M, Opdam N J M, Loomans B A C. The amalgam free dental school. J Dent 2004; 32: 371-377.

28. Department of Health. Precautionary advice on dental amalgam fillings. (Press release). London: Department of Health, 1998. http://www.dh.gov.uk/en/ Publicationsandstatistics/Pressreleases/DH_4024646 